\title{
Revizyonda cerrahi yaklaşımlar
}

\author{
Surgical approach in revision
}

\author{
Mehmet Faruk Çatma ${ }^{1}$, Serhan Ünlü ${ }^{1}$, Murat Altay ${ }^{2}$ \\ 1SB Dışkapı Yıldırım Beyazıt Eğitim ve Araştırma Hastanesi Ortopedi ve Travmatoloji Kliniği, Ankara \\ ${ }^{2}$ Karabük Üniversitesi Tıp Fakültesi Ortopedi ve Travmatoloji Anabilim Dalı, Karabük
}

\begin{abstract}
Revizyon total diz artroplasti ameliyatlarında eski implantların çıkarılması ve yeni implantların yerleştirilmesi için, yeterli bir görüş sağlanması önemlidir. Bu sayede, komplikasyonlardan ve teknik hatalardan kaçınılmış olunur. Birçok revizyon ameliyatında, standart mediyal parapatellar kesi yeterli olmaktadır. Ancak, sert dizlerde (özellikle $<60^{\circ}$ diz fleksiyon varlığında) patella yeterince döndürülemiyorsa, alternatif yaklaşımlar gerekebilmektedir. Ekstansör mekanizma gevşetilmeden cerrahiye devam edilecek olunursa, patellar tendon yırtığı veya kopma kırığı görülme olasılığı artacaktır. İdeal bir cerrahi yaklaşımda; implantlar kolay çıkarılmalı, ekstansör mekanizma korunmalı, erken dönemde eklem hareket açıklığı sağlanmalıdır. Geçmişten günümüze kadar çok çeşitli yöntemler tanımlanmıştır. Bu yazıda, ekstansör mekanizmanın tenolizi, kuadriseps kesisi (quadriceps snip), V-Y kuadriseps döndürme (turndown), patellar döndürme (turndown), tibial tüberkül osteotomisi, femoral soyma (peel), mediyal epikondil osteotomisi ve muz gibi soyma (banana peel) yöntemleri yeniden gözden geçirilip, birbirlerine göre olan üstünlükleri ve olumsuz yönleri ele alınacaktır.
\end{abstract}

Anahtar sözcükler: ekstansör mekanizma; düzeltme, cerrahi; diz artroplastisi, total; yaklaşım
It is of great importance to reach a satisfying agreement on the removal of the existing implants and the placement of new ones for revision total knee replacement. This avoids possible complications and technical failures. In many revision replacements, standard medial parapatellar incision is found to be enough. Yet if patellas of tough knees (in particular, cases of knee flexion of $<60^{\circ}$ ) aren't rotated enough, alternative approaches may be necessary. If surgery is maintained without releasing the extensor mechanism, risk of patellar tendon tear or fracture increases. An ideal surgery entails an easy removal of prosthesis, protection of extensor mechanism, and early range of motion. Various techniques have been defined since a long time. In this article, the methods of tenolysis of extensor mechanism, quadriceps snip, V-Y quadriceps turndown, patellar turndown, tibial tubercle osteotomy, femoral peel, medial epicondylar osteotomy, and banana peel will be examined; their pros and cons will be discussed.

Key words: extensor mechanism; revision, surgical; knee arthroplasty, total; approach
P rimer total diz artroplastisi; sağkalımı ve hasta memnuniyeti yüksek bir cerrahi işlemdir. Revizyonu gerektirecek aseptik sorunlar; periprostatik kırık, komponent gevşemesi, artrofibrozis, patellofemoral sorunlar, polietilen aşınması olarak sayılabilir. ${ }^{[1]}$ Primer total diz artroplastisinden dört yıl sonra revizyon oranı yaklaşık $\% 4$, yedi yıl sonra ise $\% 4,5-8$ olarak gösterilmiştir. ${ }^{[2]}$

Revizyon total diz protezi cerrahisi planlanan hastada; önceki ameliyatları, drenaj ve yara problemleri, ilk ve sonraki ameliyatları arasındaki süre, hareket kısıtlılığı ve sistemik hastalıkları sorgulanmalıdır. Muayenede; önceki cilt kesileri, eklem hareket açıklığı, ekstansiyon kaybı ve patella pozisyonu değerlendirilmelidir. ${ }^{[1]}$
Standart yaklaşımların tek başına kullanılması dizin yeteri kadar açılımını sağlamayabilir. Sistematik bir yaklaşım, revizyon cerrahisi sırasında karşılaşılabilecek birçok sorunun başarılyla üstesinden gelinebilmesini sağlayacaktır. ${ }^{[3]}$ Nazik bir şekilde yumuşak dokuya yaklaşım, implantların kemikte defekt oluşturmadan güvenli bir şekilde çıkarılması, mevcut kemik stoğunun belirlenmesi ve yeni komponentlerin doğru yerleştirilmesi için, distal femur ve tibial platonun yeterli açılımı kritik önem taşır. Bu olgularda, sıklıkla skar dokusunun ve doku elastikiyetinin azalmış olması nedenleriyle, yeterli açıım sağlamak zor olabilmektedir. Kuadriseps tendonunun kalınlaşması ve patellar tendon etrafindaki yapışıklıklar, açıımı biraz daha zor hale getirir. ${ }^{[4]}$

- İletişim adresi: Op. Dr. Serhan Ünlü, SB Dışkapı Yıldırım Beyazıt Eğitim ve Araştırma Hastanesi Ortopedi ve Travmatoloji Kliniği, İrfan Baştuğ Cad. Altındağ, Ankara Tel: 0532 - 4035002 e-posta: serhanunlu@yahoo.com

- Geliștarihi: 8 Nisan $2015 \quad$ Kabul tarihi: 8 Nisan 2015 
Daha önce açılmış bir diz eklemindeki anatomik tuzakların iyi bilinmesi, iyi sonuç alınmasında önemli rol oynar. Revizyon ameliyatı sırasında; cilt kesisinin seçimi, ekstansör mekanizmanın korunması, kollateral bağların durumu ve nörovasküler yapıların korunması, başlıca önem verilmesi gereken konulardır. ${ }^{[1,4,5]}$

Diz çevresi kanlanmasının bilinmesi, cilt ve patella avasküler nekrozunun önlenmesinde önemlidir. Diz çevresindeki cildi besleyen kan akımının kaynağı asimetriktir ve fasya altından çıkan damarlarla anastamoz yapar. Perforatör damarlar, sıklıkla safen arter ve desandan geniküler arterden kaynaklanır ve dizin mediyal tarafinda yer alır. Bu nedenle, derin ve yüzeyel fasyadaki geniş diseksiyonlar, derinin kan akımını bozar. ${ }^{[3]}$

Hastada mevcut tek orta hat kesisi varsa, bu kesi, çoklu longitudinal kesiler varsa, en dıştaki kesi kullanılmalıdır. Eski kesi ile yeni kesi arasındaki mesafe, mümkünse en az $6 \mathrm{~cm}$ olmalıdır. Bu sayede mediyaldeki beslenme korunmuş olur. Transvers bir kesi varsa, buna $90^{\circ}$ dik, long bir kesi kullanılabilir. Kesi, buna rağmen $60^{\circ}$ 'den daha çok akut açılanma yapıyorsa, kanlanma risk altındadır (Şekil 1). ${ }^{[5-7]}$

Revizyon cerrahisinde, özellikle proksimal tibianın anteromediyal bölümü, beslenme açısından risk altındadır. Bu bölgede cilt altı dokunun ince olması ve yeterli kas desteğinin olmaması nedenleriyle cilt nekrozu gelişecek olursa, mediyal gastroknemius rotasyon flebi uygulanması gerekebilir. Bu nedenle, bu bölgenin diseksiyonuna daha titiz yaklaşılmalı, künt diseksiyondan kaçınılmalıdır. ${ }^{[7]}$

Patellanın beslenmesi; desandan genikuler arter, superior mediyal, inferior mediyal, superior lateral, inferior lateral genikuler arter ile anterior tibial rekürren arterin yaptığı çepeçevre pleksus ile sağlanır (Şekil 2).

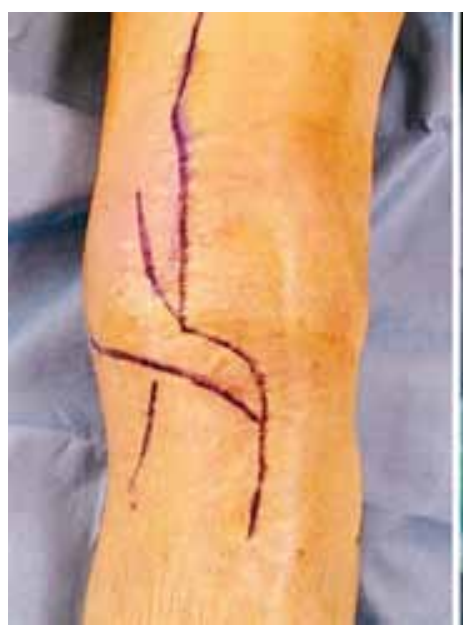

Şekil 1. Cilt kesisi kullanımı.
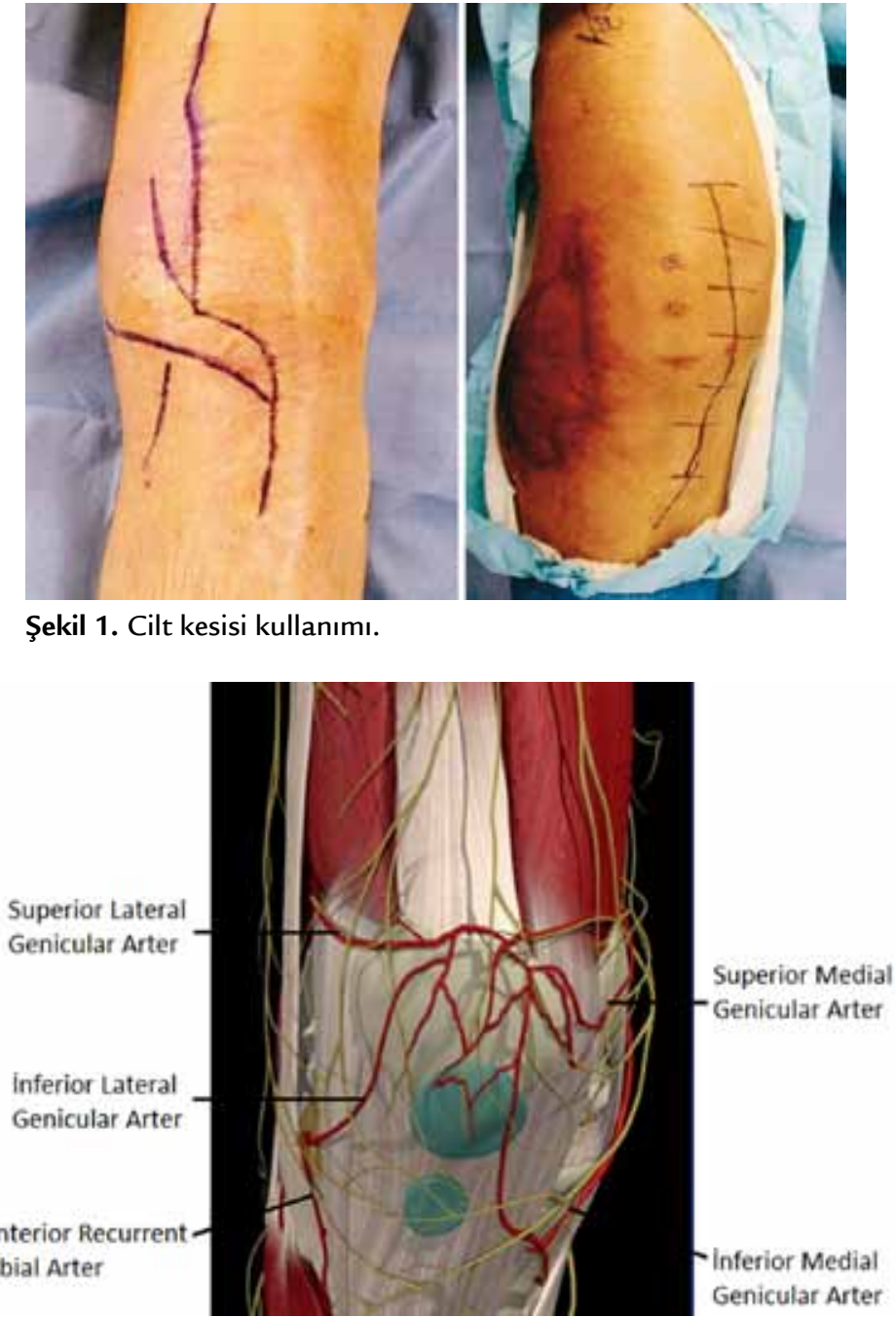

Şekil 2. Diz çevresi damar ağı. 
Standart mediyal parapatellar yaklaşım, pleksusun mediyalinden gelen beslenmeyi azaltacak ve infrapatellar yağ yastığı eksizyonu ile de, superior lateral genikuler arter ile anterior tibial arterin rekürren dalından gelen beslenme azalacaktır. Bunlara lateral gevşetme de eklenirse; superior genikuler arterden gelen beslenme de azalıp, patellar avasküler nekroz ihtimali artmış olacaktır. Eğer lateral gevşetme uygulanacaksa, bunun kapsülün içinden yapılması, bu beslenmeyi korumada önemlidir. ${ }^{[5,7]}$

Popliteal arter, popliteal fossa boyunca ilerleyen nörovasküler yapıların en derininde olanıdır. Popliteal fossanın laterelinde konveks olarak devam eder ve bu seviyede, tibial sinirin lateralinde yer alır. Popliteal arter, kapsülün arkasında genikuler dallara ayrilır ve posterior kapsülün subperiostal elevasyonu, femur ve tibianın mediyal ve lateralinde güvenli olarak düşünülür. Diz fleksiyonu popliteal arter için koruma sağlamaz, çünkü eklem seviyesinde posterior kapsüle bağlıdır. ${ }^{[7,8]}$

Revizyon cerrahisinde, tibial sinir, peroneal sinirden daha çok risk altındadır. Peroneal sinir ise, traksiyon, kompresyon ve laserasyon şeklinde yaralanabilir. Lateral gevşetme esnasında uygulanabilecek biseps tendon gevşetilmesinden mümkünse kaçınılmalıdır. ${ }^{[5]}$

\section{AÇILIM PRENSIPLERi}

Birçok yazar, diz revizyonununda ekstansör mekanizmanın gevşetilmesini, ameliyatın başarısında ana unsur olarak görmektedir. Patellanın tutunma noktaları, kuadriseps ve patellar tendon ile yaptığı bağlantılardır. ${ }^{[5]}$ Revizyon diz cerrahisinde, bu bağlantıların bütünlügü sıklıkla geniş yaklaşımlarda bozulur. Eklem sertliği, birçok revizyon cerrahisinde önemli bir sorundur ve bazı durumlarda daha geniş yaklaşımlara gereksinim duyulabilir. ${ }^{[8]}$ Birçok revizyon cerrahisinde, kuadriseps kesisinin (snip) eklendiği standart mediyal parapatellar yaklaşım tercih edilir.

Standart mediyal parapatellar yaklaşım ile açılan bir dizde, takiben eklem içindeki skar dokusunun geniş bir şekilde eksizyonu yapılmalıdır. Mediyal ve lateral çıkmazlara uygulanacak kapsamlı bir sinovektomi ile birlikte, mediyal retinakulum ve mediyal kollateral bağ, tibiadan subperiosteal olarak gevşetilmelidir. Yüzeyel kollateral bağ korunarak, mediyal gevşetme ilerletilebilir. Eğer kollateral bağ zarar görürse, kısıtlayıcı bir protez kullanılması gerekir. Patellar tendonun tibial tüberkülden kopması engellenmelidir. Ayağın dış rotasyona alınması ve gerekirse tendonun bir pin ile tespiti, tendonun ayrılmasını engelleyecektir. Revizyon cerrahisinde, patellanın devrilmesi yerine subluksasyonunun kullanılması da patellar tendonun hasarını önleyecektir.

\section{EKSTENSIL (GENIŞ) AÇILIM}

Ekstensil yaklaşım; proksimal ve distalde oluşuna göre iki gruba ayrılabilir. Proksimalde uygulanan yaklaşımlar; ekstansör mekanizmanın tenolizi, rektus kesisi (snip), kuadriseps devirme (turndown), mediyal epikondiler osteotomi ve femoral soymadır (peel). Distalde uygulanan yaklaşımlar ise, tibial tüberkül osteotomisi ve muz gibi soymadır (banana peel). Ameliyat sırasında hangi yöntemin uygulanması gerektiğini, patellanın ve ekstansör mekanizmanın durumları gösterecektir. Patella baja durumunda, distalde uygulanan yaklaşımlar tercih edilmelidir. Eğer patella normal veya yukarı pozisyonda ise, proksimal gevşetme yöntemleri uygulanabilir. Bu yaklaşımların tamamı, ekstansör mekanizmayı belirli derecelerde bozacaktır; bu nedenle, sadece gerekli durumlarda kullanılmalıdır. Hangi aşamada, nasıl bir teknikle açılım sağlanacağına, ameliyatın başında karar verilmelidir. Bu derlemede; bu tekniklerin özellikleri, birbirlerine karşı üstünlükleri ve olumsuz yönleri ele alınacaktır.

\section{Ekstansör Mekanizmanın Tenolizi - Patellar İnversiyon Yöntemi}

$\mathrm{Bu}$, revizyon cerrahisinde en sık uygulanan yöntemdir: Standart mediyal parapatellar artrotomi sonrasında tam bir sinovektomi yapılır; patellar tendon ve tibial tüberküldeki yapışıklıklar gevşetilir; patellar yağ dokusu ve patella çevresi fibrotik dokular çıkarılır; lateral çıkmazdaki skar dokuları çıkarılır; suprapatellar bölgedeki kuadriseps yapışıklıkları gevşetilir; tibia dış rotasyona alınarak patellar tendon üzerindeki gerim azaltılır; gerekirse bir pin yardımıyla tendon ayrılmadan kemiğe tutturulur; daha sonra patella dışa döndürülür veya çevrilmeden, bir Hohman ekartörü yardımıyla kenara alınır; ${ }^{[9]}$ diz dikkatli bir şekilde fleksiyona alınır. Sharkey ve arkadaşları, bu yöntemi uyguladıkları 198 hastada, yara problemi veya patella avasküler nekrozu görmemişlerdir. Komplikasyon olarak; patella çevresi fibrozis $(\% 7,2)$, hematom $(\% 4,8)$, genel anestezi altında manipülasyon $(\% 3,9)$ ve patella subluksasyonu $(\% 1,4)$ görülmüştür. ${ }^{[10]}$ Rehabilitasyonu, primer diz protezinden farklı değildir.

\section{Rektus Kesisi (Kuadriseps Snip)}

Insall, 1988 yılında tanımlamıştır. ${ }^{[11]}$ Bu yaklaşımda, standart mediyal parapatellar artrotomi sonrasında, kesi proksimale ve laterale doğru $45^{\circ}$ 'lik eğimle uzatılır ve kuadriseps tendonunun proksimal-lateralinde sonlandııılır (Şekil 3). Bu sayede, patellanın kan dolaşımı bozulmamış olur. Kesi sonrası, uç uca kapatmaktan çok, kenar kenara kapatma tercih edilmelidir. Standart mediyal parapatellar yaklaşım ile rektus kesisini (snip) 


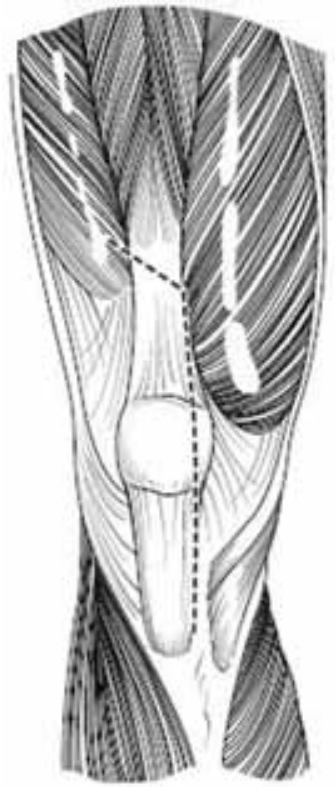

Şekil 3. Kuadriseps kesisi (snip).
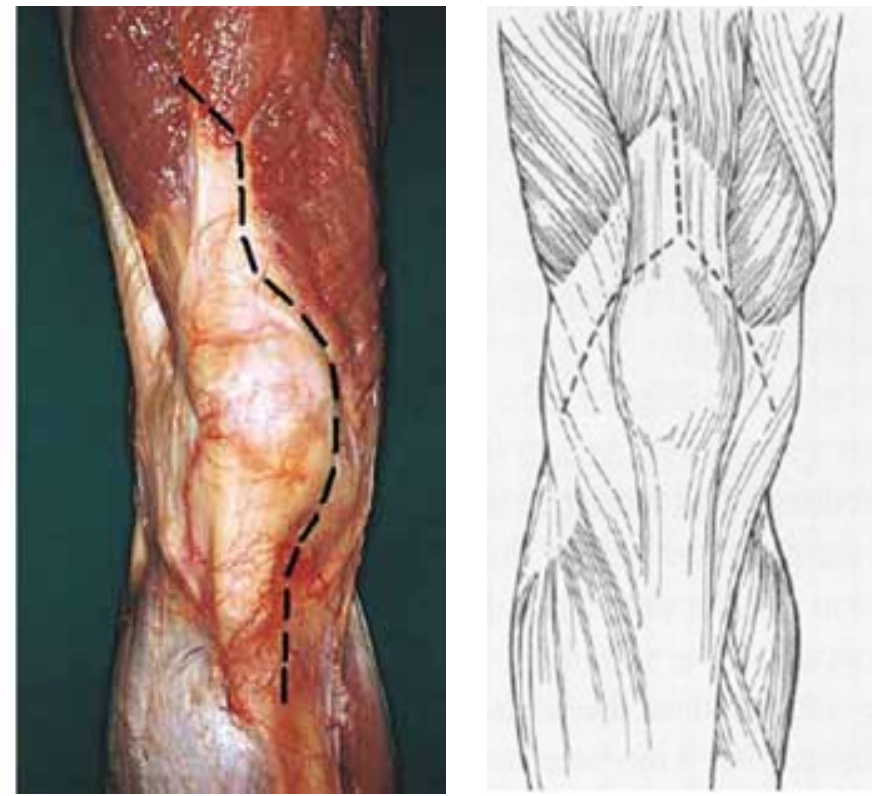

Şekil 4. V-Y Döndürme (turndown) (Coonse-Adams yaklaşımı). karşılaştıran birçok çalışmada, bunların aralarında belirgin bir farklılık olmadığı bildirilmektedir. Günümüzde, standart yaklaşım ile yeterli açılımın sağlanamadığı durumlarda sıklıkla kullanılmaktadır. ${ }^{[11]}$ Kuadriseps snip yaklaşımı güvenlidir ve özel bir tespit gerekmemesi ise avantajıdır. Uygulaması kolaydır ve ameliyat sonrası dönemde, standart yaklaşıma göre farklı bir rehabilitasyon programı uygulamayı gerektirmez. Sonuçları da primer diz protezine benzerdir.

\section{V-Y Kuadriseps Çevirme}

\section{(Coonse-Adams yaklaşımı)}

Illk olarak, 1943 yılında Coonse ve Adams tarafından tanımlanmıştır. ${ }^{[12]} \mathrm{Bu}$ yaklaşımın ana hedefi, ekstansör mekanizmanın uzatılması gerektiği ve daha basit yaklaşımlarla yeterli açılımın sağlanmadığı ciddi-sert dizlerdir. Mediyal parapatellar yaklaşım, standart şekilde yapılır, mediyal parapatellar kesi yukarıda vastus mediyalis ve lateralisin yapışma yerine kadar uzatılır. Kuadriseps tendonu, vastus lateralisin yapışma yeri seviyesinde, yaklaşık $45^{\circ}$ 'lik bir açı ile distal ve lateral yönde kesilir. Kuadriseps tendonu üzerinde ters $\mathrm{V}$ harfi oluşturulmuş olur. Bu şekilde, patellayı da içine alan bir flep elde edilir. Patella aşağıya devrilerek cerrahi alan genişletilmiş olur. Bu yaklaşımla, ters $\mathrm{V}$ şeklindeki kesiyi ters $\mathrm{Y}$ şekline çevirerek, kuadriseps tendonu uzatılmış ve çok geniş bir açılım sağlanmış olur. Ameliyattan sonra, mediyal artrotomi kesisi kapatılır. Ancak, patellar uyumun sağlanması için lateral kesi gerekiyorsa kapatılmayabilir. Böylece, lateral retinakuler gevşetme yapılmış olur. (Şekil 4). Bu kesinin en olumsuz yönü, lateral superior genikuler arterin korunamamasıdır. Ameliyattan sonra, diz iki hafta ekstansiyonda tutulur, daha sonra altı hafta içinde $60^{\circ}$ fleksiyona getirilir. Hastaya, tam ekstansiyon sağlanamayabileceği konusunda bilgi verilmelidir. Günümüzde çok tercih edilmemektedir.

\section{Patellar Döndürme (Turndown) (Modifiye Coonse-Adams yaklaşımı)}

Coonse-Adams yaklaşımının, özellikle superior genikuler arter üzerine olumsuz etkileri nedeniyle, birçok yazar tarafından farklı modifikasyonlar önerilmiştir. 1983 yılında Insall, 1985 yılında Scott ve Siliski'nin tanımladıkları yöntemler, superior genikuler arteri korumaya yönelik değişiklikler içermektedir. ${ }^{[5,13]} \mathrm{Bu}$ modifikasyonlarda, standart mediyal parapatellar artrotomiye $45^{\circ}$ açı ile, distal-laterale doğru ikinci bir kesi yapılır. Ancak, bu ikinci kesi fazla uzun tutulmaz ve patella proksimalinde superior genikuler arteri koruyacak şekilde sonlandırılır (Şekil 5, 6).

Ameliyat sonunda, diz $90^{\circ}$ fleksiyonda iken, tendon emilmeyen dikişlerle tamir edilir. Mediyal parapatellar kesi her zaman tamir edilebilir. Patellofemoral uyum için, gerektiğinde oblik lateral kesi kapatılmayabilir. Ameliyat sonrası dönemde, bacak yaklaşık iki hafta ekstansiyonda tutulur. Illk hafta, $30^{\circ}$ aktif fleksiyon pasif ekstansiyona izin verilir. Aktif fleksiyon, her hafta $10^{\circ}$ arttırılır. Hastalar, ameliyat sonrası altı hafta aktif ekstansiyon yapmamaları konusunda bilgilendirilir. 


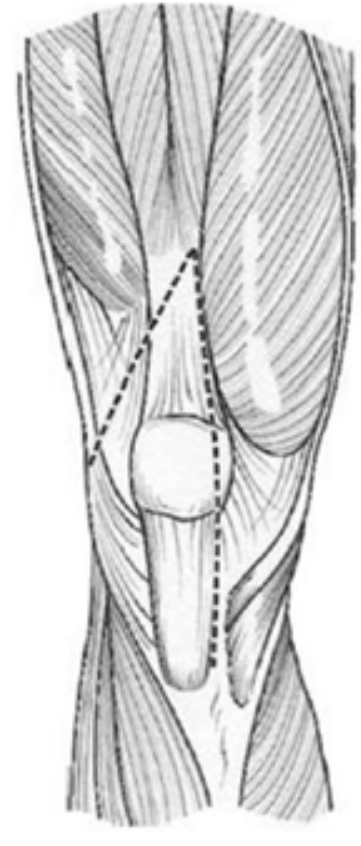

Şekil 5. Patellar döndürme (turndown) (Modifiye Coonse-Adams yaklaşımı).

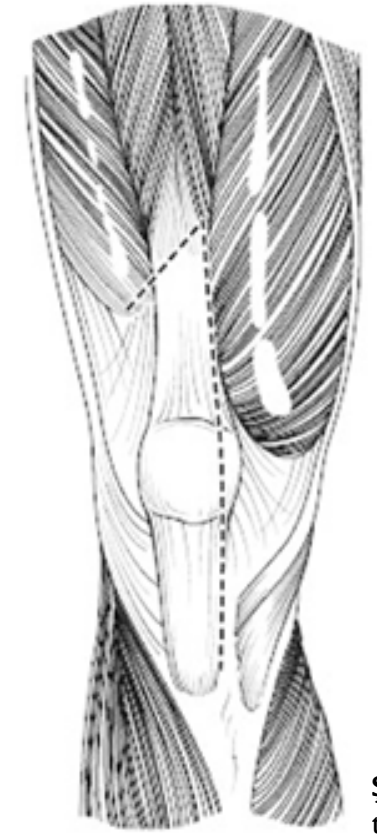

Şekil 6. Scott ve arkadaşlarının tanımladığı kuadriplasti tekniği.
Bu yaklaşımın avantajı, revizyon cerrahisinin herhangi bir safhasında, eğer gerekliyse, rutin standart yaklaşıma eklenebilmesidir. Önemli derece fleksiyon kontraktürü $\left(35-45^{\circ}\right)$ ve fleksiyonu kısıtlı olan $\left(65-75^{\circ}\right)$ hastalarda endikedir. Böylece, kuadriseps kası uzatılmış olur.

Daha önce geçirilmiş ameliyatlara bağlı olarak, kuadriseps kasının proksimal tendinöz bölümünün kalitesi kötü ise bu yaklaşım kontrendikedir.

\section{Tibial Tüberkül Osteotomisi}

$\mathrm{Bu}$ osteotomi, ekstansör mekanizmada skar ve yapışıklıklar olan, daha önce proksimal yumuşak doku girişimleri yapılmış veya patella baja olan hastalarda tercih edilmelidir. Ayrıca, bu yaklaşımla patellofemoral dizilimi düzeltmek ve sıkı tutunmuş tibial komponenti de kolay çıkartmak mümkündür. illk olarak, 1983 yılında Dolin tarafindan, diz artroplasti olgularında kullanılmıştır. ${ }^{[14]}$ Orijinal tarifinde, tibial tüberkül mediyal kenarından 4,5 cm'lik bir parça kesilir ve laterale doğru devrilir; sonrasında vida ile tespit edilir. Dolin, serisinde, \%23 komplikasyon, \%11 tendon rüptürü oranı raporlamıştır. Whiteside, bu tekniği modifiye etmiştir. ${ }^{[15]}$ Tüberkülün mediyalinden laterale doğru, $8 \mathrm{~cm}$ uzunluğunda, $2 \mathrm{~cm}$ genişliğinde ve $1 \mathrm{~cm}$ kalınlığında kemik parçası kaldırmıştır. İnce bir testere ile, kesi, tüberkülün mediyalinden ve distalinden, transvers ve konik şekil verilerek oluşturulur. Bu kesiye dik olarak, proksimalde ve distalde eğri bir osteotom yardımıyla transvers birer kesi yapılır ve parça laterale doğru devrilir.
Parçanın lateral kısmının kas ve periost bağlantısının sağlam kalmasına özen gösterilir. Literatürde, tibial tüberkül osteotomisinin boyutları konusunda ortak bir görüş bulunmamaktadır. Değişik yayınlarda; 70-100 mm uzunluğunda, $10-20 \mathrm{~mm}$ genişliğinde, $10-20 \mathrm{~mm}$ kalınlığında osteotomiler tanımlanmıştır. Büyük bir parça çıkarıldığında tibia kırığı riski, küçük bir parça çıkarıldığında ise parçanın yukarıya kayma riski vardır. Chinzei ve arkadaşları, yaptıkları çalışmada, çıkarılacak kemik parçanın $60 \mathrm{~mm}$ uzunluğunda, $20 \mathrm{~mm}$ genişliğinde ve $10 \mathrm{~mm}$ kalınlığında olmasını önermişlerdir. ${ }^{[16]}$

Tespit yönteminin başarısı için, alınan kemik parçasının şekli de önemlidir: Proksimal ucunun basamakIı, distal ucunun sivri olması önerilmektedir (Şekil 7). $\mathrm{Bu}$ parçanın tekrar tutturulmasında, kablo, vida ya da güçlendirilmiş sütür materyalleri kullanılabilir. Bazı yazarlar, vida kullanımından sonra parçanın tespiti ile ilgili sorunlar bildirmişlerdir. Bu nedenle, son zamanlarda vida yerine iki veya üç adet tel ile tespit daha çok kullanılmaktadır.

Bu yaklaşımın avantajı, patellar kan akımını riske etmemesidir. Ancak, bu yöntem sonrası karşımıza, kaynama problemleri ve hareket kısıtlılığı çıkabilmektedir. Literatürde, tespit problemleri dışında, yara problemleri de bildirilmiştir. Whiteside, tel ile tespit yöntemiyle, sadece iki proksimal tüberkül kopma kırığı görmüştür. Bu osteotomi, osteoporozda ve büyük tibial kemik defektleri varlığında kontrendikedir. Romatoid artrit hastalarında, komplikasyon oranı nispeten daha yüksektir. Illk altı hafta, açı ayarlı dizlik ile bastırılması önerilmektedir. 


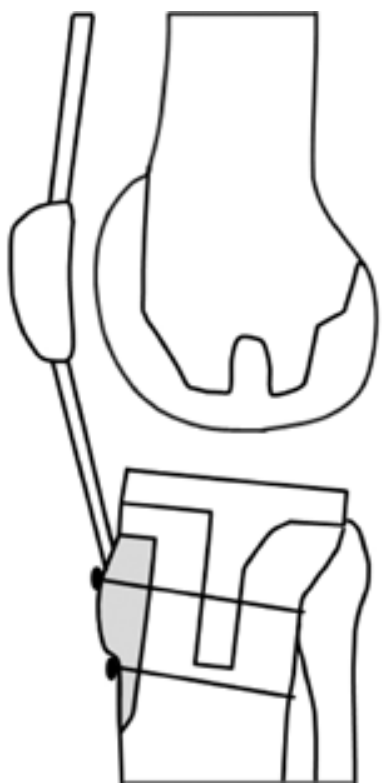

Şekil 7. Tibial tüberkül osteotomi (proksimal uç basamaklı, distal uç sivri kesilmiş).

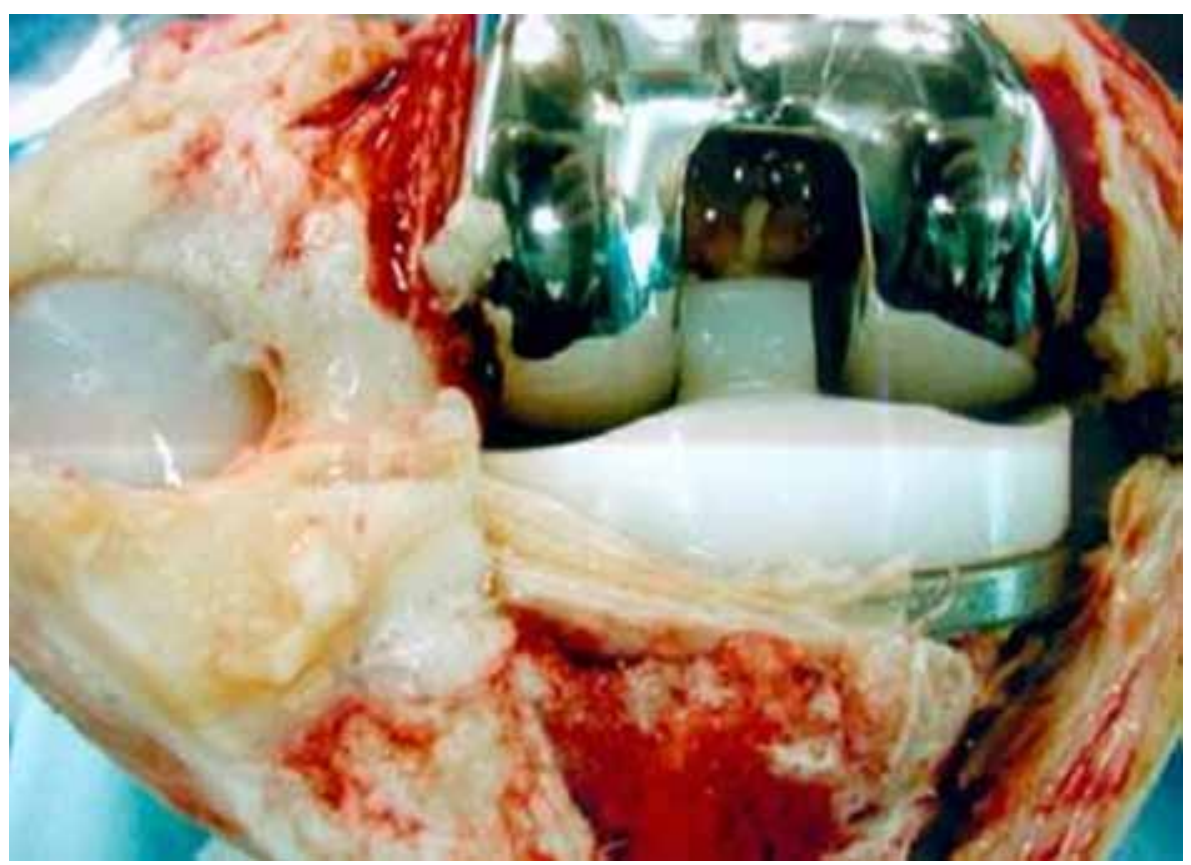

Şekil 8. Lahav’ın tanımladığı, muz gibi soyma (banana peel) tekniği.

\section{Femoral Soyma (Peel)}

Windsor ve Insall tarafından tanımlanmıştır. ${ }^{[6]} \mathrm{Bu}$ yaklaşımda, mediyal ve lateral kollateral bağlarla birlikte bütün yumuşak dokular, distal femurdan subperiosteal olarak sıyrılır. Revizyon diz cerrahisi sırasında, aşırı skar oluşumu nedeniyle diz yeterince fleksiyona alınamıyorsa uygulanır. Bu teknikte, distal femoral avasküler nekroz riski yüksektir. Günümüzde çok tercih edilen bir yöntem değildir. Lavernia ve arkadaşlarının yaptığı çalışmada, 101 hastaya femoral soyma tekniği uygulanmış ve \%17 komplikasyon oranı bulunmuştur. ${ }^{[17]}$ Literatürde, \%30'lara varan komplikasyonlar bildirilmiştir.

\section{Mediyal Epikondiller Osteotomi}

Engh tarafından tanımlanmıştır. ${ }^{[2]}$ Kapsüler gevşetmeye rağmen diz fleksiyonunun sınırlı olduğu olgularda endikedir. Diz $90^{\circ}$ fleksiyonda iken, epikondil palpe edilir; adduktor magnus kası bulunur ve yapıştığı yerin üzerinden $4 \mathrm{~cm}$ çapında $1 \mathrm{~cm}$ kalınlığında bir epikondil parçası çıkarılır ve yüzeyel kollateral bağ, mediyal epikondilin superior yapıları bu parçada kalır. Diz tam dış rotasyonda iken, disseksiyon genişletilmelidir. Daha sonra, diz $90^{\circ}$ fleksiyonda iken ayrılmış olan bu kemik parça, vida ya da sütür ile tutturulmalıdır. Her iki epikondil osteotomisi de, nadir endikasyonlarda gerekir. Diz füzyonu sonrası yeterli açılım sağlamak için, lateral epikondilden de $3 \mathrm{~cm}$ çapında parça çıkarılarak açııı daha da genişletilebilir.

\section{Banana Peel}

Illk olarak Lahav tarafından tanımlanmıştır. ${ }^{[18]}$ Standart mediyal parapatellar kesi yapılır; daha sonra proksimalde kuadriseps snip uygulanır; dikkatli ve keskin bir disseksiyonla, patellar tendon, tibianın anteriorundan kontrollü bir şekilde soyulmaya başlanır. Patella, nazikçe döndürülmeye çalışılır. Bu aşamada, bir periostal sıyırıcı ile, patellar tendon tibiadan tek bir tabaka halinde kaldırılır. Bu metodun avantajı, proksimal ve distalden gevşetme yapıldığı için yeterli bir cerrahi görüş sağlanmasıdır (Şekil 8). Lahav, 102 hastaya bu yöntemi uygulamış, takipleri sırasında herhangi bir ekstansiyon kaybı veya tendon rüptürü tespit etmemiştir.

\section{SONUÇ}

- Eski kesileri göz önüne alarak, en dıştaki kesiyi tercih edin.

- En az yumuşak doku açılımıyla yeterli görüş sağlayan yaklaşımı planlayın.

- Yumuşak dokuda keskin disseksiyon kullanın ve flebi kalın tutarak beslenmeyi bozmayın.

- Tüm yapışıklık ve fibrotik dokuları gevşetin; suprapatellar bölge, mediyal ve lateral çıkmazı debride edin.

- Tibianın posteromediyal köşesini gevşetirken, tibiayı aşamalı olarak dış rotasyona alın. 
- Lateral retinakuler gevşetme gereken durumlarda, gevşetmeyi içten ve erken aşamada gerçekleştirin.

- Her olguda patellayı çevirmeye zorlamayın.

- Patellar tendon ve mediyal kollateral bağ yapışma yeri tehlike altındaysa, kuadriseps snip uygulayın.

- Patella baja ve eski ameliyatlara bağlı olarak, ekstansör mekanizmada skar ve yapışıklıklar olan sert dizlerde, tibial tüberkül osteotomisini tercih edin.

\section{KAYNAKLAR}

1. Della Vale CJ, Berger RA, Rosenberg AG. Surgical exposures in revision total knee arthroplasty. Clin Orthop Relat Res 2006;446:59-68.

2. Engh GA. Medial epicondylar osteotomy: a technique used with primary and revision total knee arthroplasty to improve surgical exposure and correct varus deformity. Instr Course Lect 1999;48:153-6.

3. Younger AS, Duncan CP, Masri BA. Surgical exposures in revision total knee arthroplasty. J Am Acad Orthop Surg 1998;6(1):55-64.

4. WolffAM, Hungerford DS, Krackow KA, Jacobs MA. Osteotomy of the tibial tubercle during total knee replacement. A report of twenty six cases. J Bone Joint Surg Am 1989;71(6):848-52.

5. Scott RD, Siliski JM. The use of a modified V-Y quadricepsplasty during total knee replacement to gain exposure and improve knee flexion in the ankylosed knee. Orthopedics 1985;8(1):45-8.

6. Windsor RE, Insall JN. Exposure in revision total knee arthroplasty: the femoral peel. Tech Orthop 1988;3(2):1-4. CrossRef
7. Trousdale RT, Hanssen AD, Rand JA, Cahalan TD. V-Y quadricepsplasty in total knee arthroplasty. Clin Orthop Relat Res 1993;(286):48-55.

8. Aglietti P, Windsor RE, Buzzi R, Insall JN. Arthroplasty fort the stiff or ankylosed knee. J Arthroplasty 1989;4(1):1-5.

9. Fehring TK, Odum S, Griffin WL, Mason JB. Patella inversion method for exposure in revision total knee arthroplasty. J Arthroplasty 2002;17(1):101.

10. Sharkey P, Homesley D, Shastri S, Jacoby S, Hozack W, Rothman R. Results of revision total knee arthroplasty after exposure of the knee with extensor mechanism tenolysis. J Arthroplasty 2004;19(6):751-6.

11. Garvin KL, Scuderi G, Insall JN. Evolution of the quadriceps snip. Clin Orthop Relat Res 1995;(321):131-7.

12. Coonse K, Adams JD. A new operative approach to the knee joint. Surg Gynecol Obstet 1943;77(4):344-7.

13. Insall JN. Surgical approaches. In: Insall JN, Scott WN, Windsor RE, Kelly MA, Aglietti P, editors. Surgery of the Knee, 2nd ed. New York: Churchill Livingstone; 1993. p.135-48.

14. Dolin MG. Osteotomy of the tibial tubercle in total knee replacement. A technical note. J Bone Joint Surg Am 1983;65(5):704-6.

15. Whiteside LA. Exposure in difficult total knee arthroplasty using tibial tubercle osteotomy. Clin Orthop Relat Res1995;(321):32-5.

16. Chinzei N, Ishida K, Kuroda R, Matsumoto T, Kubo S, Iguchi T, Chin T, Akisue T, Nishida K, Kurosaka M, Tsumura N. Tibial tubercle osteotomy with screw fixation for total knee arthroplasty. Orthopedics 2014;37(4):367-73. CrossRef

17. Lavernia C, Contreras JS, Alcerro JS. The peel in total knee revision: exposure in the difficult knee. Clin Orthop Relat Res 2011;469(1):146-53. CrossRef

18. Lahav A, Hofmann AA. The "banana peel" exposure method in revision total knee arthroplasty. Am J Orthop (Belle Mead NJ) 2007;36(10):526-9. 